\title{
Topological Specificity in Reinnervation of the Superior Colliculus by Regenerated Retinal Ganglion Cell Axons in Adult Hamsters
}

\author{
Yves Sauvé, Hajime Sawai, and Michael Rasminsky \\ Centre for Research in Neuroscience, Montreal General Hospital and McGill University, Montreal, Quebec, \\ H3G 1A4, Canada
}

In normal rodents there is a precise topology of the retinocollicular projection, the nasotemporal and ventrodorsal axes of the retina being respectively projected onto the caudorostral and mediolateral axes of the contralateral superior colliculus (SC). We evaluated the distribution of regenerated retinal ganglion cell (RGC) axon terminals in the SC of adult hamsters in which an unbranched peripheral nerve graft was directed from the retina to the contralateral SC. Responses to visual stimulation of individual RGCs were recorded from terminal arbors of their regenerated axons in the reinnervated SC. Retinal positions of these RGCs were inferred from the locations of their visual receptive fields. At some sites in the reinnervated SC, axon terminal arbors converged from widely separated RGCs. Conversely, axon terminal arbors at widely separated sites in the SC could emanate from contiguous RGCs. To assess whether any tendency for order was superimposed on the apparent disorganization of the regenerated projection, we evaluated the relative positions of pairs of RGC terminals in the $S C$ in relation to the relative retinal locations of the corresponding pairs of RGCs. Among the 983 pairs of RGCs able to be evaluated from nine animals studied 30-60 weeks after grafting, there was a statistically significant $3 / 2$ tendency for the more nasally situated of two RGCs to project its terminal more caudally in the SC than that of the more temporally situated RGC. A similar tendency toward appropriate organization was not found with respect to the ventrodorsal axis of the retina and the mediolateral axis of the SC.

Key words: electrophysiology; hamster; peripheral nerve graft; regeneration; retinal ganglion cell; retinotopy; superior colliculus; synapse; tectum
In adult rodents, axotomized retinal ganglion cell (RGC) axons are capable of long-range regrowth along peripheral nerve grafts and can invade the superior colliculus (SC) where they form well differentiated and persistent synapses (Vidal-Sanz et al., 1987, 1991; Carter et al., 1989, 1994), which can mediate trans-synaptic excitation of SC neurons in response to light (Keirstead et al., 1989; Sauvé et al., 1995). The reconstituted retinocollicular projection retains at least two aspects of specificity of innervation characteristic of the normal retinocollicular projection: (1) regenerating RGC axons reinnervate the superficial retinorecipient layers of the SC rather than the deeper layers that normally receive no direct retinal input (Carter et al., 1989; Sauvé et al., 1995), and (2) regenerating RGC axons form synapses on dendrites and dendritic spines of SC neurons in the same proportions that occur during normal innervation (Carter et al., 1989, 1994).

A further aspect of specificity of retinal innervation of the mammalian SC is the topology of the retinocollicular projection. As in anamniotes, RGC axons emanating from nasal, temporal, ventral, and dorsal retina project respectively to the contralateral caudal, rostral, medial, and lateral tectum or SC (Siminoff et al., 1966; Tiao and Blakemore, 1976b; Finlay et al., 1978). This

\footnotetext{
Received Feb. 8, 2000; revised Oct. 17, 2000; accepted Nov. 2, 2000.

This work was supported by the Canadian Medical Research Council, studentship awards from Fonds pour la Formation de Chercheurs et l'Aide à la Recherche, the Rick Hansen Man in Motion Fund to Y.S., and a travel award from the Cell Science Research Foundation (Japan) to H.S. We thank Janet Laganière for technical assistance, Dr. Y.-C. Wang and Dr. Tom Zwimpfer for preparation of some of the grafted animals, and Dr. Mikhail Abrahamowicz and Roxane de Berger for statistical advice.

Correspondence should be addressed to Dr. Michael Rasminsky, Centre for Research in Neuroscience, Montreal General Hospital, 1650 Cedar Avenue, Montreal, Quebec, H3G 1A4, Canada. E-mail: michael.rasminsky@mcgill.ca.

Copyright (C) 2001 Society for Neuroscience 0270-6474/01/210951-10\$15.00/0
}

retinotopic organization is substantially reproduced during spontaneous reinnervation of the tectum by regenerated RGC axons in frogs and fish (Attardi and Sperry, 1963; Gaze and Jacobson, 1963; Stuermer and Easter, 1984; Udin and Fawcett, 1988). Although two-thirds of RGCs reinnervate the tectum in lizards, anatomical tracings indicate that regenerated projections lack retinotopic order (Beazley et al., 1997). In rodents, topographic organization was also absent during innervation of the SC of neonatal rats by transplanted fetal retinae (Galli et al., 1989).

To investigate the possibility that topographic specificity is expressed during reinnervation of the SC in adult mammals, we examined the distribution of terminal arborizations of regenerated RGC axons in hamsters with peripheral nerve grafts linking one retina and the contralateral SC. We have shown previously that recordings of unitary visual responses within the SC in such animals identify the sites of terminal arborizations of individual regenerated RGC axons and the neurons with which they make synapses (Sauvé et al., 1995). We were thus able to correlate the position of individual RGCs in the retina, identified on the basis of the positions of their visual receptive fields, with the electrophysiologically defined positions in the SC of the terminal arborizations of their respective regenerated axons.

\section{MATERIALS AND METHODS}

\section{Preparation of animals with peripheral nerve grafts}

Autologous peripheral nerve grafts linking the eye and the SC were prepared in 90- to 120-d-old female golden hamsters (Mesocricetus auratus; weight, 100-120 gm) (Carter et al., 1989; Sauvé et al., 1995). The results presented here are concerned exclusively with the topology of the projection regenerated from the eye to the SC and for this reason are taken from the subset of those animals reported previously (Sauvé et al., 1995 ) in which one end of the nerve graft was sutured to the stump of the 
optic nerve and the other end was inserted as a single undivided branch into the anterolateral aspect of the contralateral SC. The lateral border of the SC is delimited by blood vessels forming a V shape. The graft was always inserted at the apex of the $\mathrm{V}$ so that there was some small difference from animal to animal in the precise anteroposterior position of the graft tip with respect to the SC. Although it would have been preferable to insert the distal end of the graft so as to maintain the rostrocaudal trajectory characteristic of normally developing retinocollicular axons, this was precluded by the constant presence of blood vessels that delimit the rostral border of the SC. In some cases the distal end of the nerve graft was inserted into the SC 7-8 weeks after anastomosis of the graft to the optic nerve stump; in others the anastomosis to the optic nerve and insertion of the distal end of the graft into the SC were accomplished in a single procedure. The diameter of the graft at the point of insertion was 200-400 $\mu \mathrm{m}$. Physiological experiments were performed 30-60 weeks after anastomosis of the graft to the optic nerve stump. We report results from the nine grafted animals in which six or more SC units with distinct visual receptive fields were identified and from three intact adult hamsters.

\section{Preparation of animals for physiological experiments}

Animals were prepared for physiological experiments as described previously (Sauvé et al., 1995) under anesthesia with 25\% urethane (1.25 $\mathrm{mg} / \mathrm{kg}$, i.p.) that was supplemented as necessary throughout the experiment with additional doses $(0.25 \mathrm{mg} / \mathrm{kg}$, i.p. $)$. After enucleation of the nongrafted eye and exposure of the SC by aspiration of the overlying cortex, the animal's head, held in a nose bar, was positioned to make the surface of the SC as horizontal as possible. The rostrocaudal axis of the $\mathrm{SC}$ was assumed to correspond to the sagittal suture. The pupil of the grafted eye was dilated with $0.06 \%$ topical atropine, the eye was immobilized with three equidistant 6-0 sutures in the conjunctiva attached to the animal frame, and the cornea was protected with a nonrefractive contact lens. Repeated recordings from the same site in the SC of intact animals established that the positions of receptive fields remained stable for several hours with this method of immobilization of the eye.

\section{Identification and localization of unit responses}

The exposed SC was systematically explored with carbon fiber microelectrode recordings on a grid of 100-200 $\mu \mathrm{m}$ in the rostrocaudal and mediolateral planes (Sauvé et al., 1995). At each recording site where a response was found to visual stimulation with an EEG flash (Keirstead et al., 1989; Sauvé et al., 1995), an attempt was made to identify units responsive to stimulation of discrete receptive fields. The visual field was systematically searched by moving spots of light across a translucent tangent screen positioned $20 \mathrm{~cm}$ from the eye, orthogonal to the projection of the optic disk as viewed by an ophthalmoscope. Responsive units with on, off, or on-off responses were found at depths between 0 and 400 $\mu \mathrm{m}$ from the surface of the SC (Sauvé et al., 1995). In all experiments an attempt was made to scan enough of the surface of the SC so that the area within which unitary responses were seen was bounded by recording sites at which no visual responses could be elicited. This would enhance the chances of obtaining a representative sampling of the reinnervation of the SC by regenerated RGC axons.

We assume the light-elicited unitary responses recorded with the carbon fiber electrodes used for these experiments to reflect potentials generated (1) by the terminal arbors of regenerated axons in the vicinity of the neurons that they innervate and (2) by the postsynaptic neurons themselves but not by axons en passant remote from their terminals (Sauvé et al., 1995). Recordings from normal animals with these electrodes reveal an orderly distribution of receptive fields (see Results) and no suggestion of recordings from axons projecting toward targets remote from the recording site. Furthermore, repeated attempts to record responses to visual stimulation with these electrodes either directly from the graft or from the brachium of the SC in normal animals were unsuccessful, suggesting that our electrodes did not readily record axonal responses.

In the SC of reinnervated animals, responses to light consist of bursts of impulses in which individual elements comprise two major components: an initial spike-like terminal potential arising from the presynaptic axonal terminal arborization and an ensuing longer duration focal synaptic potential arising from the neurons innervated by the terminal arborization (Sauvé et al., 1995). The same unit was occasionally recorded from adjacent recording sites separated by $100-200 \mu \mathrm{m}$ or from different depths at the same recording site over distances of up to 250 $\mu \mathrm{m}$; both presynaptic and postsynaptic elements were not constantly present in all recordings [see Sauvé et al. (1995), their Fig. 5A]. Some of our recordings may have thus reflected terminal potentials recorded from terminal arbors as much as $150-200 \mu \mathrm{m}$ remote from the region of synapses with their target neurons in the SC [see Sauvé et al. (1995), their Fig. $5 B$ ]. Receptive fields overlapping each other by $>50 \%$ and recorded from sites separated by $200 \mu \mathrm{m}$ or less in the SC were considered to be associated with the same RGC if the response properties were identical at both recording sites. In such cases the position of the terminal arbor was assumed to be midway between or among the sites at which the arbor was recorded.

Within the SC, regenerated RGC axon terminals form arbors having several different configurations (Carter et al., 1998). We have no way of knowing whether some of these configurations give rise to more easily recorded terminal potentials or whether appropriately arrayed terminals are more or less likely to be more easily recorded than are inappropriately arrayed terminals. Our comparisons, of necessity, imply that our sampling of RGC terminals, although undoubtedly incomplete, is reasonably random.

\section{Localization of RGCs and their projection sites}

To correct for the distortion of visual space attendant on plotting receptive fields on a tangent screen, we calculated the projection onto the tangent screen of a spheroidal surface centered on the eye. The position of the center of each receptive field could then be identified both with respect to a linear coordinate system and with respect to the projected system. Each receptive field could thus be assigned both linear and angular coordinates to define its displacement from the projection of the optic disk. These angular coordinates would correspond precisely to linear displacements on the surface of the retina, assuming the retina to be hemispheric. The relationship between these coordinate systems is described by the expressions:

$$
\theta_{h}=\arctan \left[x / \sqrt{ }\left(y^{2}+d^{2}\right)\right] \text {, and } \theta_{v}=\arctan \left[y / \sqrt{ }\left(x^{2}+d^{2}\right)\right],
$$

where $d$ is the distance from the eye to the tangent screen, $x$ and $y$ are horizontal and vertical displacements, respectively, on the tangent screen from the projection of the optic disk, and $\theta_{h}$ and $\theta_{v}$ are the angles of displacement from the horizontal and vertical, respectively, in radians. The calculated angular coordinates were used to determine relative positions of receptive fields that could then be replotted on a grid corresponding more closely to the linear displacements in the retina.

The nasotemporal axis of the eye is conventionally defined as coinciding with the axis of the medial and lateral rectus muscles. For seven grafted hamsters (including four in which fewer than six responses were found), the displacement of the nasotemporal axis of the eye from the horizontal, measured at the conclusion of the experiment, ranged from 46 to $28^{\circ}\left(46,38,35,33,33,32\right.$, and $\left.28^{\circ}\right)$. For those animals in which the position of the medial and lateral recti was not precisely determined, there was thus a potential error in the determination of the position of this axis of up to $18^{\circ}$, although most displacements from the horizontal were clustered within a few degrees of $35^{\circ}$. An algorithm was developed to recalculate the coordinates of receptive fields for any assumed displacement of the nasotemporal axis from the horizontal.

\section{Assessment of the relative positions of regenerated $R G C$ axon terminals in the reinnervated $S C$}

The area of reinnervation of each SC represented a small proportion (at most approximately one-third) of the total area of the SC, centered around the site of graft insertion (Sauvé et al., 1995). The site of insertion of the nerve graft into the SC varied within a few hundred micrometers from animal to animal, some insertions being more rostral and others more caudal within the $2 \mathrm{~mm}$ rostrocaudal extent of the SC. For these reasons it would have been inappropriate to attempt to make interanimal comparisons of the absolute collicular sites of projection of axons emanating from particular areas of the retina. Instead we assessed the possibility of retinotopic influences by comparing for each animal the relative positions of regenerated axon terminals in the reinnervated SC.

The premise of this comparison is that if two RGC axons entering the $\mathrm{SC}$ in the same graft can respond to putative cues determining spatial organization, the terminals of these axons should deploy themselves appropriately with respect to one another at a higher-than-chance frequency. With respect to each RGC, the surrounding retina can be divided into nasal, temporal, dorsal, and ventral regions. Similarly the SC can be divided into caudal, rostral, lateral, and medial regions with respect to each projection site. The relative axonal projections of each 


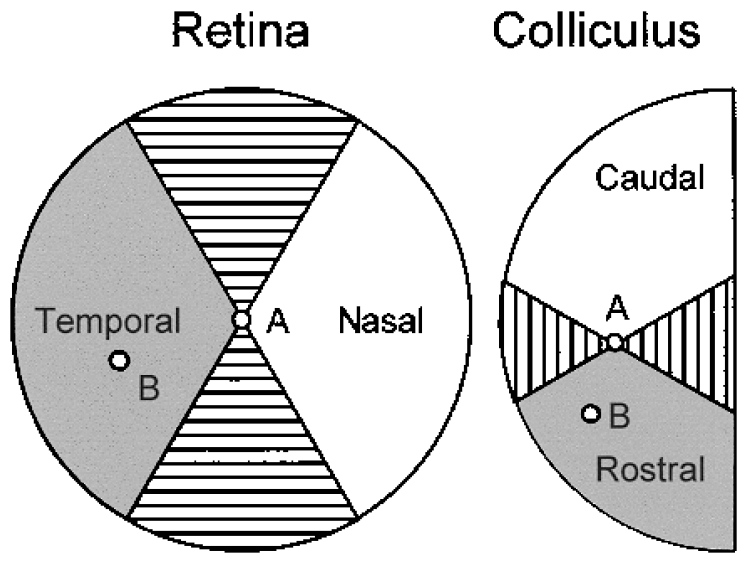

Figure 1. Method for assessing the appropriateness of relative axonal projections of pairs of RGCs. The position of an index RGC and its axonal terminal on the contralateral SC are indicated by the small circles labeled $A$. RGCs temporal to the index RGC (within the shaded area of the retina; e.g., at site $B$ ) should project their axon terminals rostral to the projection of the index RGC (i.e., in the vicinity of site $B$ within the corresponding shaded area of the SC). Such pairs of projections and the corresponding projections from relatively nasal retina to relatively caudal $\mathrm{SC}$ (white areas) are designated appropriate. Pairs of projections in which the RGC in more temporal retina projects more caudally in the SC or in which the RGC in more nasal retina projects more rostrally in the SC are designated inappropriate. Within the areas that are hatched, relative displacements of RGCs or their projections cannot be confidently identified in the nasotemporal axis of the retina or the rostrocaudal axis of the $\mathrm{SC}$ with respect to the index position $A$ (see text). Pairs of cells including such displacements are unclassifiable.

pair of RGCs can then be scored as appropriate, inappropriate, or unable to be evaluated as illustrated in Figure 1 .

Within the nasotemporal axis of the retina and rostrocaudal axis of the $\mathrm{SC}$, an appropriately projecting pair is one in which the more nasal of two RGCs projects more caudally in the SC. An inappropriately projecting pair is one in which the more nasal of two RGCs projects more rostrally in the SC. In certain cases, particularly when the RGCs or their terminals are widely separated in the axis orthogonal to the axis of interest, these judgments will be questionable. If the measured positions of two regenerated RGC axon terminals are separated by, for example, 1 $\mathrm{mm}$ in the mediolateral axis of the SC but by only, for example, $200 \mu \mathrm{m}$ in the rostrocaudal axis, any judgment about the relative displacement of the terminals in the rostrocaudal axis will be somewhat suspect. For this reason, we arbitrarily excluded as unable to be evaluated all pairs in which the RGCs or their axonal projections were displaced with respect to one another outside of the $\pm 60^{\circ}$ bounding the axes of interest (Fig. 1). Widening the angle of acceptability would have admitted consideration of more pairs at the price of increased uncertainty about the validity of all of the classifications. Narrowing the angle of acceptability would have increased the certainty of the classifications at the price of reducing the number of pairs included in the analysis and the power of the statistical analysis. Also unclassifiable were pairs in which two RGCs with identical locations projected to different areas in the SC and pairs in which two separated RGCs projected to the same site in the SC.

Two numeric analyses were used to score the relative projections of RGCs with regenerated axons.

Scoring of pairs. All possible pairs of RGCs were considered, and the relative projections of each pair was scored as appropriate, inappropriate, or unable to be evaluated. This yielded large numbers for statistical analysis but had the disadvantage that the contribution of a single RGC placed in an extreme position within the axis of interest in relation to other RGCs could excessively weight the score in an appropriate or inappropriate direction.

Scoring of RGCs. The total number of appropriate, inappropriate, and unable to be evaluated pairs was compiled for each RGC that was then assigned a net score of appropriate or inappropriate, determined by whether it participated in a majority of appropriate or inappropriate pairs. If the numbers of appropriate and inappropriate pairs were equal, the RGC was not scored. This method in effect averaged the appropri- ateness of the projection(s) of each RGC in relation to all of its neighbors that could be evaluated. This method yielded much smaller numbers, i.e., at most one score per RGC, and did not distinguish between RGCs projecting appropriately in relation to all as opposed to a small majority of its neighbors. However, it had the advantage of more equitably balancing the contribution of each RGC.

\section{Retrograde labeling of RGCs with axons regenerated into peripheral nerve grafts}

Six animals with peripheral nerve grafts apposed to the eye but not inserted into the SC were anesthetized $25-35$ weeks after grafting. In each animal the graft was cut $2 \mathrm{~cm}$ from the eye and teased toward the eye into two well separated branches. A small piece of Gelfoam (Upjohn, Kalamazoo, MI) soaked in a $3 \%$ aqueous solution of fast blue (FB; Dr. Illing, Gmbh Company) was applied to one branch, and a small piece of Gelfoam soaked in $2 \%$ fluorogold (FG; Fluorochrome, Inc.) dissolved in a solution of dimethylsulfoxide (ICN Biochemicals, Montreal, Quebec, Canada) in sterile $0.9 \%$ saline was applied to the other branch. The wound was closed, leaving the Gelfoam pieces in place, and the animals were allowed to recover from anesthesia. Seven days later, animals were perfused (Sauvé et al., 1995), and the retinae were removed and wholemounted to be examined under epifluorescence by the use of an ultraviolet filter to reveal FB- and FG-containing RGCs.

\section{RESULTS}

\section{Normal SC}

The distribution of receptive fields corresponding to recording sites in the contralateral SC is illustrated in Figure 2 for an intact animal that was representative of the three animals examined. The distribution corresponds to that described previously for the rodent (Siminoff et al., 1966; Tiao and Blakemore, 1976b; Finlay et al., 1978); nasal retina is represented caudally, and dorsal retina is represented laterally on the surface of the SC. When the receptive fields are displayed with the system of angular coordinates plotted linearly (Fig. $2 B, D$ ), it is apparent that there is a consistent relationship between the nasotemporal axis of the retina and the rostrocaudal axis of the $\mathrm{SC}$ for the entire retina and SC (Fig. 2B,C); the relationship between the ventrodorsal axis of the retina and the mediolateral axis of the $\mathrm{SC}$ varies, depending on the position in the retina and SC (Fig. 2D,E).

For the normal animal illustrated in Figure 2, 1454 of 1461 (99.5\%) of the pairs of RGCs able to be evaluated had appropriately arrayed projections in the rostrocaudal axis of the SC; 885 pairs were unable to be evaluated according to our exclusion criteria. Within the mediolateral axis of the SC, 1124 pairs of RGCs had appropriately arrayed projections with respect to their ventrodorsal origin in the retina (i.e., the more dorsally situated RGC projected more laterally in the SC), none were inappropriately arrayed, and 1222 pairs were unable to be evaluated according to our exclusion criteria. All 69 RGCs had net appropriate projections within both the rostrocaudal and mediolateral axes of the SC.

\section{The reinnervated SC}

Receptive field positions and corresponding recording sites are illustrated in Figure 3 for an animal in which 61 receptive fields were recorded. This, the largest number of receptive fields recorded in any animal, represents a substantial proportion of the several hundred RGC axons that usually regrow into such nerve grafts (Sauvé et al., 1995). Receptive fields representing RGCs in all four quadrants of the retina were found in reinnervated SCs. Two aberrations from a well ordered topology are immediately apparent for the animal illustrated in Figure 3. (1) At a given site in the reinnervated SC, responses could be recorded to illumination of as many as nine different receptive fields distributed in the four quadrants of the visual field, indicating that the regenerated 
A

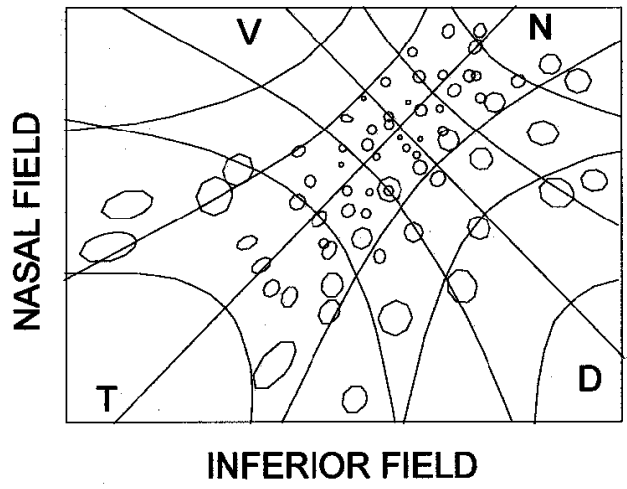

B
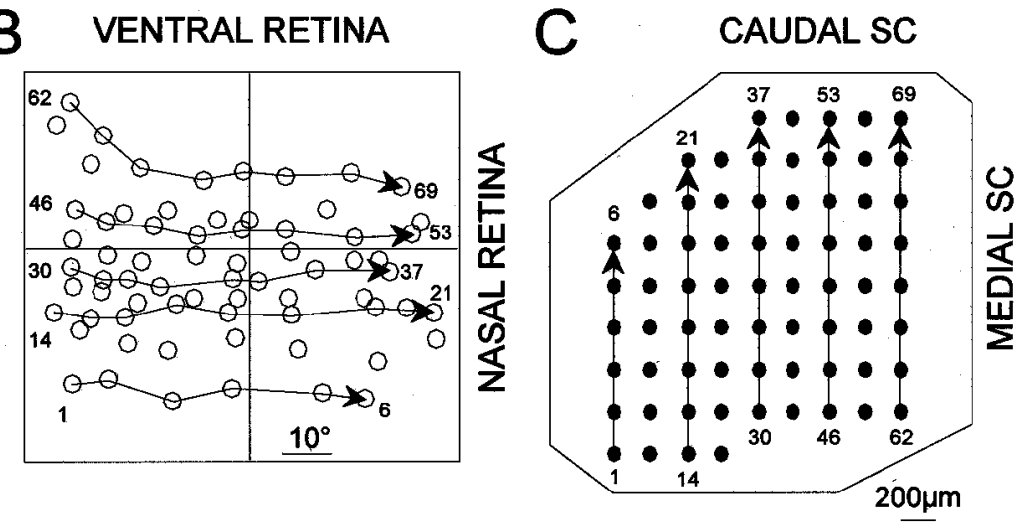

D

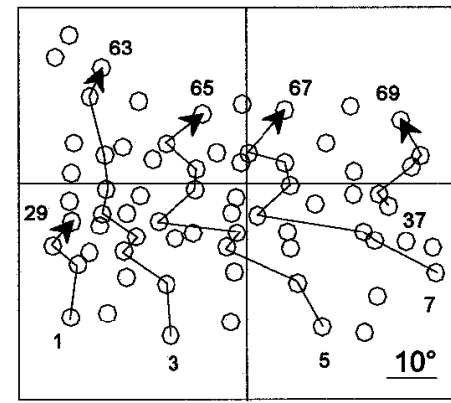

DORSAL RETINA

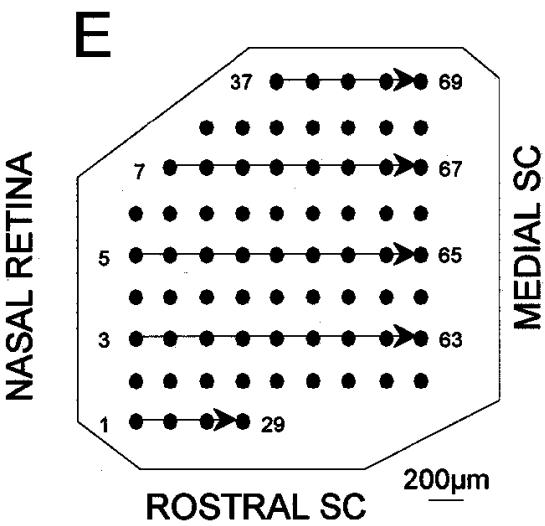

Figure 2. A, Multiunit receptive fields were recorded from the left eye of a normal hamster, plotted on a tangent screen $20 \mathrm{~cm}$ from the eye, and viewed from the side of the screen opposite to the animal. The nasotemporal axis of the eye, defined by the position of the medial and lateral rectus muscles, is indicated by the line labeled NT. The projection of the optic disk is at the intersection with the orthogonal dorsoventral axis of the eye (line labeled $D V)$. The calibration grids delineate $20^{\circ} . B, D$, The positions of these receptive fields are replotted as the corresponding positions on the retina with angular coordinates represented on a linear scale. $C, E$, The corresponding recording sites within the contralateral right SC are indicated. The numbers indicate the association of each receptive field with a recording site. Displacements from rostral to caudal of projection sites in the SC ( panel $C$ ) are associated with parallel displacements from temporal to nasal of RGC positions in the retina (panel $B$ ) irrespective of the position in the retina or the SC. Displacements from lateral to medial of projection sites in the SC ( panel E) are associated with less parallel displacements of RGC positions from dorsal to ventral in the retina ( panel $D)$.

terminals of RGCs widely distributed in the retina could arborize in the same area of the SC; and (2) responses to illumination of contiguous areas of the retina were recorded in widely separated sites within the SC, indicating that neighboring RGCs can project to different areas of the SC.

Despite the absence of a clear-cut organization in the reinnervation of the SC, the question arises as to whether some tendency toward normal retinotopy was retained.

\section{Distribution of regenerated RGC axon terminals in the rostrocaudal axis of the SC}

The results from nine animals analyzed with respect to the nasotemporal displacement of RGCs in the retina and the rostrocaudal displacement of projections of these RGCs in the SC are summarized in Table 1 . In the cases in which there was uncertainty about the precise orientation of the eye (animals 1-6), results were computed for orientations of the nasotemporal axis at $1^{\circ}$ intervals within the range of possible deviations of this axis from horizontal $\left(46-28^{\circ}\right)$. The results presented for each animal are those giving the lowest proportion of appropriate-toinappropriate projections.

Of the 983 pairs that could be evaluated, 600 were appropriately and 383 were inappropriately oriented (Table 1), representing a proportion of appropriately oriented projections of $61 \%$ or a ratio of $\sim 3 / 2$ in favor of the predicted orientation. This is significantly different from random orientation $(p<0.0005, t$ test for the proportion in a single population).

Of the 139 RGCs, 94 had net appropriate projections, 35 had net inappropriate projections, and 10 could not be scored (Table 1 ), a proportion of net appropriately oriented RGC projections of $73 \%$ or a ratio of $>2 / 1$ in favor of the predicted orientation $(p<$ $0.0005, t$ test for the proportion in a single population).

Because of the large variation in the number of RGC projections recorded in individual animals and the possibility that putative orienting effects could be systematically more strongly expressed in some animals than in others, we further examined the data by using the generalized estimating equations (GEE) approach (Liang and Zeger, 1986) as implemented in the SAS procedure GENMOD. The exchangeable covariance structure of errors was assumed, implying that all observations from the same animal are expected to be equally correlated with each other, a standard assumption for nested designs (Liang and Zeger, 1986). With a null hypothesis that the numbers of appropriate and inappropriate projections were equal, the possibility that there were more appropriate than inappropriate projections was assessed by using the estimated intercept of the GEE model in which an intercept different from zero implies a difference from an equal probability of the two possible outcomes examined. Normal approximation was used to obtain the $95 \%$ confidence 
A

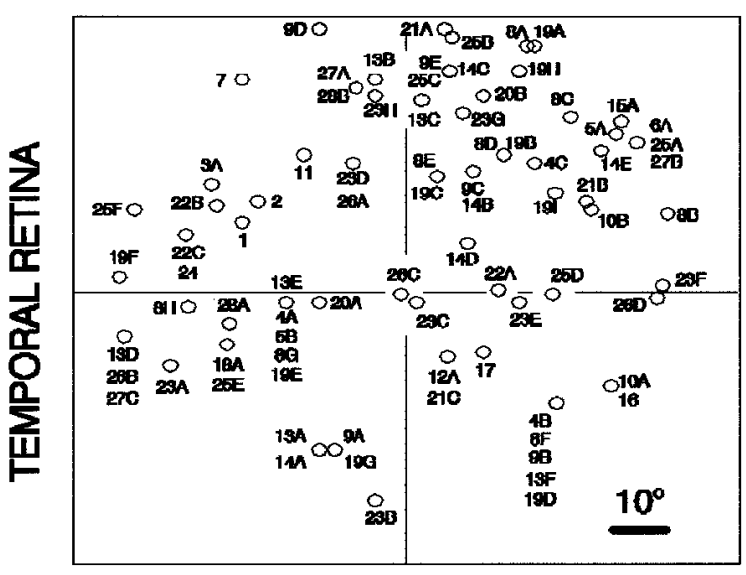

C

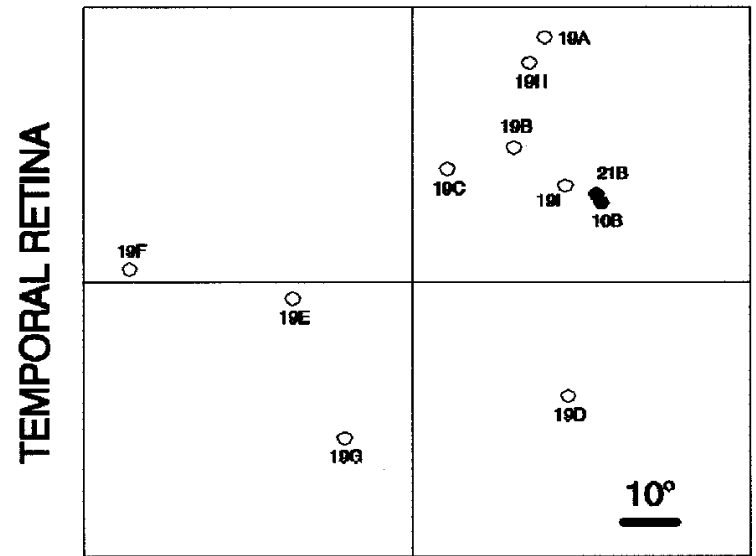

DORSAL RETINA
B CAUDAL SC

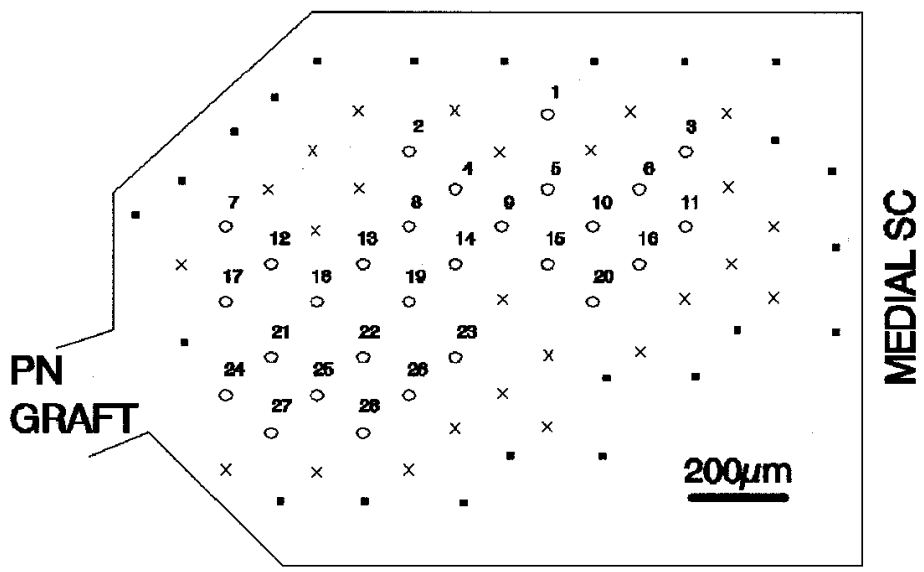

D

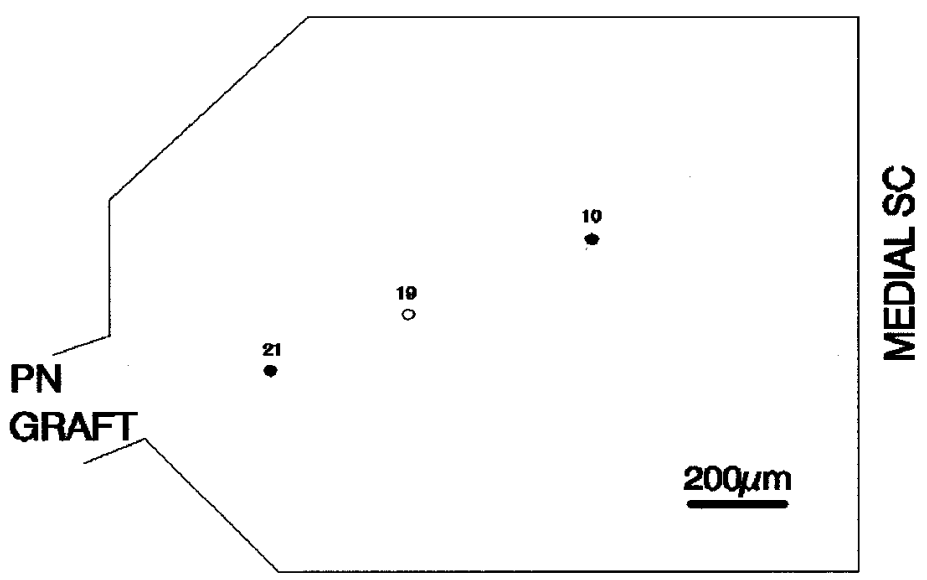

ROSTRAL SC

Figure 3. Positions of RGCs in the left retina and the projection sites of their respective axon terminals in the contralateral right SC of a grafted animal. Numbers refer to the recording sites in the SC. Letters indicate multiple receptive fields recorded at a single SC site. $A$, The positions of RGCs are inferred from the positions of the visual receptive fields as described in Figure 1. The positions of RGCs are plotted on a linear scale in degrees from the optic disk, located at the intersection of the nasotemporal and ventrodorsal axes. $B$, In the diagram of the SC, the numbered open circles indicate recording sites at which unitary responses were recorded, crosses indicate sites at which responses to flash were recorded but receptive fields could not be identified, and filled squares are sites at which no visual response could be recorded. $C, D$, The lower diagrams, extracted from the upper diagrams $(A, B)$, show projection of nine widely separated RGCs to the same recording site (site 19) in the SC (open circles) and projection of two neighboring RGCs to widely separated recording sites (sites 10,21) in the SC (filled circles). PN, Peripheral nerve.

intervals bracketing the calculated intercept, and a $Z$ statistic, calculated as the ratio of the estimated intercept to its SE, was used to test the hypothesis that there was a significant difference in the proportion of appropriate and inappropriate projections.

This statistical approach also demonstrated a significant difference from random orientation, appropriate projections being more frequent than inappropriate projections when the comparison was made either for pairs of RGCs ( $p=0.0055$; intercept of 0.59 , with $95 \%$ confidence limits that intercept lies between 0.172 and 1.00) or for individual cells ( $p=0.0018$; intercept of 0.97 , with $95 \%$ confidence limits that intercept lies between 0.36 and 1.58).

In some cases there were projections from a given site in the retina to two or more sites in the SC or from multiple sites in the retina to the same site in the SC. Such pairs would be eliminated from consideration in our tabulation of the data. For this reason we reexamined the data after including all such pairs in which the displacement within the retina or the SC could be evaluated. We further assumed for the purposes of this calculation that all such projections would be inappropriate. With this extremely conservative assumption, the proportion of appropriate-toinappropriate pairs of RGCs changed to 600 versus 437, and the proportion of appropriate-to-inappropriate individual RGCs changed to 85 versus 41 . These differences remain highly significant when the summed data are considered ( $p<0.0005, t$ test for the proportion in a single population). When comparisons across animals were made by use of the GEE approach, the previously noted differences persisted for pairs of RGCs ( $p=0.04$; intercept of 0.43 , with $95 \%$ confidence limits that intercept lies between 0.02 and 0.84$)$ or for individual cells $(p=0.037$; intercept of 0.72 , with $95 \%$ confidence limits that intercept lies between 0.04 and 1.41), although at lower levels of statistical significance.

As a further test of a tendency toward appropriate projection in the SC, we compared the disposition within the rostrocaudal 
Table 1. Appropriate and inappropriate projections of regenerated axons from pairs of RGCs and from individual RGCs within the SC

\begin{tabular}{|c|c|c|c|c|c|c|c|}
\hline \multirow[b]{2}{*}{ Animal } & \multirow[b]{2}{*}{$\begin{array}{l}\text { Number } \\
\text { of RGCs }\end{array}$} & \multicolumn{3}{|c|}{ Pairs of RGCs } & \multicolumn{3}{|c|}{ Individual RGCs } \\
\hline & & $\begin{array}{l}\text { Appropriate } \\
\text { projections }\end{array}$ & $\begin{array}{l}\text { Inappropriate } \\
\text { projections }\end{array}$ & $\begin{array}{l}\text { Unable } \\
\text { to be } \\
\text { evaluated }\end{array}$ & $\begin{array}{l}\text { Appropriate } \\
\text { projections }\end{array}$ & $\begin{array}{l}\text { Inappropriate } \\
\text { projections }\end{array}$ & $\begin{array}{l}\text { Not } \\
\text { scorec }\end{array}$ \\
\hline 1 & 8 & 4 & 9 & 15 & 2 & 6 & 0 \\
\hline 2 & 19 & 60 & 12 & 99 & 17 & 2 & 0 \\
\hline 3 & 9 & 12 & 0 & 24 & 8 & 0 & 1 \\
\hline 4 & 10 & 21 & 10 & 14 & 8 & 1 & 1 \\
\hline 5 & 7 & 5 & 7 & 9 & 3 & 3 & 1 \\
\hline 6 & 8 & 13 & 7 & 8 & 6 & 1 & 1 \\
\hline 7 & 11 & 16 & 14 & 25 & 4 & 5 & 2 \\
\hline 8 & 6 & 7 & 3 & 5 & 4 & 1 & 1 \\
\hline 9 & 61 & 462 & 321 & 1047 & 42 & 16 & 3 \\
\hline Totals & & 600 & 383 & 1246 & 94 & 35 & 10 \\
\hline
\end{tabular}

axis of the SC of terminals from the most nasal and most temporal RGCs. For each animal the RGCs with regenerated axons were divided into three equal groups: nasal, central, and temporal as defined by their relative positions within the retina. In all cases the numbers of RGCs in the nasal and temporal groups were taken as equal integral numbers; the number in the middle group was less if the total number of RGCs was not evenly divisible by 3. The average rostrocaudal displacement of the terminals of the nasal group of RGCs with respect to an arbitrary zero displacement was then compared with the average rostrocaudal displacement of the terminals of the temporal group of RGCs (Table 2). For six of the nine animals the more nasal RGCs projected more caudally as expected, in one animal there was no difference, and in two animals the nasal RGCs projected more rostrally. The average caudal displacement of the terminals of the more nasal RGCs with respect to the terminals of the more temporal RGCs was calculated as $87 \mu \mathrm{m}$ when the average was computed across the nine animals and as $75 \mu \mathrm{m}$ when the average was computed across the total number of RGCs in all of the nine groups compared. Because the data were not normally distributed, the Mann-Whitney rank sum test was used to determine that this average displacement was significantly different from zero $(p<$ 0.001 ) when computed across the total number of RGCs but was not significantly different from zero when computed for the nine animals taken as individuals.

\section{Distribution of regenerated RGC axon terminals in the mediolateral axis of the SC}

The distribution of projections of regenerated RGC axons was also analyzed in the ventrodorsal axis of the retina and the mediolateral axis of the SC. Of the 909 pairs that could be evaluated, 458 were appropriately and 451 were inappropriately oriented, a difference from random projection in this plane that was not statistically significant.

\section{Number and distribution of regenerating axons within the peripheral nerve graft}

If the ultimate position of regenerated RGC axon terminals within the SC is to be interpreted as reflecting an influence of putative orienting factors within the SC, the RGC axons must be known to be distributed randomly within the peripheral nerve graft before they approach the SC. The position within a retinal flat mount of cells retrogradely labeled with FG and FB from two branches of the nerve graft is illustrated in Figure 4. The flat mount was divided into five sectors, and the numbers of cells in each sector labeled with either tracer or double-labeled are enumerated in Table 3 for six animals. The average total number of RGCs that were regenerating axons into the two branches of the graft was $385 \pm 41( \pm$ SEM $),<1 \%$ of the $\sim 10^{5}$ RGCs in the adult hamster retina (Tiao and Blakemore, 1976a). An average of $22 \%$ of RGCs were double labeled, presumably reflecting axonal branching in the graft. In none of the animals was there a significant difference in the proportions of FG- and FB-labeled cells in the five sectors (Table 3). This suggests that regenerated RGC axons tended to be randomly organized within the nerve graft at the level of application of the label, as is the case for RGC axons as they reach the optic chiasm in the normally developing rodent optic nerve (Simon and O'Leary, 1991; Chan and Guillery, 1994). Because these retrograde-labeling experiments were done on animals with grafts that had not been inserted into the SC, there was no possibility that the SC could have exerted any influence on the disposition of axons within the graft. It is however possible that regenerating axons within the bridging grafts used for our physiological experiments could have been subjected to topographic cues as they approached the SC.

\section{DISCUSSION}

This study has shown that regenerating mammalian RGC axon terminals do not form a precise retinotopic map when reinnervating the SC. However, superimposed on the apparent randomness of distribution of RGC terminals, there appears to be a small but nonetheless statistically significant tendency for these terminals to array themselves appropriately within the rostrocaudal axis of the SC. Because the graft tip was placed at different locations in different animals, our assessment of topography was of necessity a comparison of the relative positions of reinnervating axon terminals for each animal rather than an identification of the absolute position of each terminal. It also must be emphasized that our method assesses terminal positions but not trajectories of regenerating RGC axons. Nonetheless, our results suggest that a factor(s) may be present in the reinnervated SC, as in the newly innervated SC, that can influence the direction of axonal growth and/or the area within which arborization and synapse formation occur.

Topographic ordering of projections during normal develop- 
Table 2. Comparisons of rostrocaudal displacement within the SC of axonal projections of nasal and temporal RGCs

\begin{tabular}{|c|c|c|c|c|c|}
\hline Animal & $\begin{array}{l}\text { Number } \\
\text { of RGCs }\end{array}$ & $\begin{array}{l}\text { Number of } \\
\text { RGGs in } \\
\text { compared } \\
\text { groups }\end{array}$ & $\begin{array}{l}\text { Average rostrocaudal } \\
\text { displacement of axonal } \\
\text { projections of most nasal } \\
\text { RGCs }(\mu \mathrm{m})\end{array}$ & $\begin{array}{l}\text { Average rostrocaudal } \\
\text { displacement of axonal } \\
\text { projections of most } \\
\text { temporal RGCs }(\mu \mathrm{m})\end{array}$ & Difference $(\mu \mathrm{m})$ \\
\hline 1 & 8 & 3 & 267 & 167 & -100 \\
\hline 2 & 19 & 7 & 125 & 383 & 258 \\
\hline 3 & 9 & 3 & 233 & 300 & 67 \\
\hline 4 & 10 & 4 & 425 & 438 & 13 \\
\hline 5 & 7 & 3 & 267 & 233 & -34 \\
\hline 6 & 8 & 3 & 183 & 467 & 284 \\
\hline 7 & 11 & 4 & 150 & 150 & 0 \\
\hline 8 & 7 & 3 & 150 & 425 & 275 \\
\hline 9 & 61 & 21 & 438 & 462 & 24 \\
\hline Average & & & & & $\begin{array}{l}87 \pm 47( \pm \text { SEM }) \text { for animals } \\
75 \pm 17( \pm \text { SEM }) \text { for all } \\
\text { RGCs in } 9 \text { groups }\end{array}$ \\
\hline
\end{tabular}

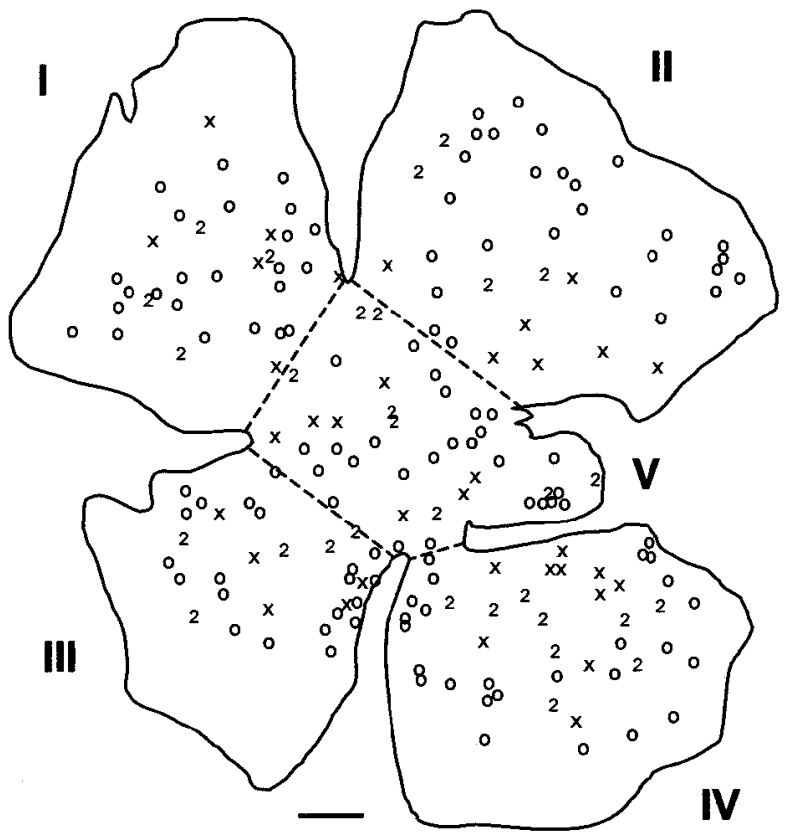

Figure 4. Camera lucida drawing of retrogradely labeled RGCs in a whole mount of a retina from which RGC axons had regenerated into a peripheral nerve graft. The graft was divided into two branches labeled with fast blue (crosses) or fluorogold (open circles). Double-labeled cells are indicated by the number 2 . The whole mounts prepared in this manner were arbitrarily divided into five approximately equal sectors $(I-V)$ as illustrated to permit evaluation of the proportions of labeled cells in various areas of the retina. Scale bar, $500 \mu \mathrm{m}$.

ment of retinofugal pathways is thought to reflect at least two processes: an initial pathfinding to the approximately correct area directed by spatially specific molecular cues as first suggested by Sperry (1963) and a subsequent phase of refinement of the projection thought to be caused by activity-dependent processes in which near simultaneous firing of neighboring RGCs (Wong et al., 1993) serves mutually to stabilize the connections of their shared projections to target neurons in the lateral geniculate nucleus (Penn et al., 1998) or tectum (Shatz, 1990; Cline, 1991). Initial pathfinding of RGC axons within the tectum may be very $\overline{\text { Table 3. Number of RGCs back-labeled with either FB, FG, or both (D) }}$ in five retinal regions of six grafted animals

\begin{tabular}{|c|c|c|c|c|c|c|c|c|c|}
\hline \multirow[b]{2}{*}{ Animal } & \multirow[b]{2}{*}{ Label } & \multicolumn{5}{|c|}{ Sector } & \multirow[b]{2}{*}{ Total } & \multirow{2}{*}{$\begin{array}{l}\chi^{2} \text { FB } \\
\text { vs FG }\end{array}$} & \multirow[b]{2}{*}{$p$} \\
\hline & & I & II & III & IV & $\mathrm{V}$ & & & \\
\hline \multirow[t]{3}{*}{1} & FB & 6 & 7 & 5 & 10 & 7 & 189 & 1.36 & 0.85 \\
\hline & FG & 24 & 27 & 21 & 26 & 26 & & & \\
\hline & $\mathrm{D}$ & 4 & 4 & 5 & 9 & 8 & & & \\
\hline \multirow[t]{3}{*}{2} & FB & 36 & 116 & 42 & 56 & 52 & 440 & 1.16 & 0.89 \\
\hline & FG & 10 & 39 & 13 & 14 & 19 & & & \\
\hline & $\mathrm{D}$ & 7 & 15 & 6 & 7 & 8 & & & \\
\hline \multirow[t]{3}{*}{3} & FB & 4 & 8 & 21 & 13 & 2 & 459 & 0.66 & 0.96 \\
\hline & FG & 15 & 25 & 69 & 32 & 6 & & & \\
\hline & $\mathrm{D}$ & 37 & 92 & 85 & 27 & 23 & & & \\
\hline \multirow[t]{3}{*}{4} & FB & 51 & 68 & 52 & 47 & 47 & 431 & 0.73 & 0.95 \\
\hline & FG & 23 & 34 & 23 & 25 & 19 & & & \\
\hline & $\mathrm{D}$ & 12 & 17 & 2 & 6 & 5 & & & \\
\hline \multirow[t]{3}{*}{5} & FB & 49 & 47 & 62 & 50 & 43 & 422 & 0.63 & 0.96 \\
\hline & FG & 26 & 21 & 26 & 24 & 22 & & & \\
\hline & $\mathrm{D}$ & 5 & 10 & 10 & 20 & 7 & & & \\
\hline \multirow[t]{3}{*}{6} & FB & 46 & 79 & 13 & 21 & 43 & 371 & 0.49 & 0.98 \\
\hline & FG & 24 & 37 & 8 & 9 & 21 & & & \\
\hline & $\mathrm{D}$ & 21 & 22 & 9 & 7 & 11 & & & \\
\hline
\end{tabular}

The average total number of back-labeled neurons is $385 \pm 41( \pm$ SEM). Relative proportions of FB- and FG-labeled cells are compared in two-way contingency tables (SigmaStat 2) to generate a $\chi^{2}$ value with $4 \mathrm{df}$. The corresponding $p$ values are the probabilities that there are no significant differences among the distributions in the five regions.

precise as in frogs and fish (Holt and Harris, 1983; Stuermer, 1988) or more exuberant and diffuse as in rodents (Simon and O'Leary, 1992a,b). Computer simulations suggest that a combination of positional cues and activity-dependent mechanisms can give rise to a very precise retinotectal topology in a variety of experimental situations (Fraser and Perkel, 1990; Honda, 1998), for example even if a molecular gradient is only transiently expressed during the initiation of innervation of the tectum (Hua et al., 1993).

During regeneration of the retinotectal pathway in frogs and fish, the initial topography is only roughly organized. Functional 
synapses are formed indiscriminately by regenerating goldfish RGC axons as they enter the tectum, but these may be unstable if inappropriately located (Matsumoto et al., 1987; Meyer and Kageyama, 1999). Projections become refined into a more precise retinotopic map over a period of several weeks by mechanisms that depend on ongoing activity in neighboring RGC axons (Udin and Fawcett, 1988; Cline, 1991).

In vitro experiments have shown that molecules with topological specificity with respect to the rostral and caudal tectum or SC are transiently expressed in the neonatal mammalian SC (Walter et al., 1987b). These topologically specific markers disappear after the retinocollicular pathway is laid down but reappear $\sim 2$ weeks after denervation of the SC (Wizenmann et al., 1993); such positionally specific markers may be more strongly expressed in deafferented SC than in embryonic SC (Bähr and Wizenmann, 1996). Our experimental results are consistent with the possibility that a gradient of such positionally specific markers could serve as an influence on the exploration of the SC by regenerated RGC axons (Baier and Bonhoeffer, 1992; Wizenmann and Bähr, 1997, 1998), either by exerting a repulsive or tropic effect on their axonal growth cones (Walter et al., 1987a,b; Boxberg et al., 1993; Nakamoto et al., 1996; Davenport et al., 1998; Ichijo and Bonhoeffer, 1998) or by influencing their branching patterns (Roskies and O'Leary, 1994). Positionally specific markers could also influence the deployment of regenerating RGC axons within the nerve graft as they approached the SC.

The question arises as to why the effects of the factor(s), if present, are so minimally expressed or so difficult to document in the reinnervated mammalian SC. Both biological and methodological considerations may be involved.

\section{Biological constraints on topographically appropriate reinnervation}

In the reinnervated $\mathrm{SC}$, the maximum extent of exploration by a regenerated RGC axon is $1 \mathrm{~mm}$ or less (Carter et al., 1994), more extensive exploration of the SC perhaps being limited by the presence of factors that are inhibitory to axonal growth (Caroni and Schwab, 1988; McKerracher et al., 1994; Smith-Thomas et al., 1994; Ghosh and David, 1997) and are present in the adult animal as well as by the developmental downregulation of growth permissive molecules (McLoon et al., 1988; Rager et al., 1996) and their receptors (Cohen et al., 1986; de Curtis and Reichardt, 1993). This is in contrast to the situation during normal development in which RGC axons from all portions of the retina initially innervate the entire SC (Simon and O'Leary, 1992a,b).

In our regeneration paradigm, $<5 \%$ of the normal total number of RGCs usually regenerate their axons, and only a portion of these reinnervate the SC (Vidal-Sanz et al., 1987); many axons terminate growth immediately after penetrating the CNS (AvilesTrigueros et al., 2000). In these conditions, with surviving RGCs widely separated in the retina and their axon terminals widely dispersed within the SC, the influence of activity-dependent mechanisms in shaping the topological pattern of innervation would be expected a priori to be much more limited than in normal development. Furthermore, with little competition among axons for synaptic sites, it is possible that inappropriately located synapses, after being formed, would be much more stable than those in the reinnervated frog or goldfish tectum. Such premature formation of synapses could in turn curtail the further exploration of the SC by regenerated RGC axons.

\section{Methodological constraints on the recognition of topographically appropriate regeneration}

Our comparisons make the implicit assumption that all regenerating axons initiate their exploration of the $\mathrm{SC}$ from the same position. This assumption is not strictly correct because pairs of regenerating axons can be separated in the rostrocaudal axis of the SC by distances approximating the width of the nerve graft at its point of entry to the SC, a distance of up to $400 \mu \mathrm{m}$. However, this separation of axons within the nerve graft militates against the demonstration of topographically appropriate reinnervation of the SC. Assume that there are factors influencing axonal growth within the rostrocaudal plane of the SC. Axons appropriately separated in this plane at the site of entry should increase this separation as they explore the SC, and their terminals will ultimately be scored as appropriately separated. Axons inappropriately separated in this plane at the site of entry will reduce the initial separation in their exploration of the $\mathrm{SC}$, but this reduction in the initial separation may or may not be sufficient to bring their terminals into a relative displacement that can be scored as appropriate. Some such pairs will thus be scored as inappropriate even if the relative trajectories of their axons were such as to reduce their initial inappropriate displacement. Because our method assesses terminal positions and not trajectories, it will invariably underestimate the effect of any factor(s) influencing the appropriate displacement of exploring regenerating axons.

\section{Organization with the mediolateral plane of the SC}

These experiments have not suggested any influence of dorsoventral position of RGCs in the retina on the mediolateral displacement of their regenerating axons in the SC. This could reflect methodological problems related to the geometry of the SC that may give rise to the apparently inconstant relationship between dorsoventral displacement of RGCs in the retina and mediolateral displacement of their terminals in the normally innervated SC (Fig. $2 D, E)$.

\section{Functional considerations}

Functional synaptic connections made in the midbrain by RGC axons regenerated via peripheral nerve grafts (Keirstead et al., 1989; Sauvé et al., 1995) can mediate pupillary responses to light (Thanos, 1992; Whiteley et al., 1998), light-avoidance behaviors in a conditioned-response paradigm (Sasaki et al., 1993), lightinduced desynchronization of EEG waves (Sasaki et al., 1996), and prepulse facilitation of auditory startle response (Sasaki et al., 1998). These behavioral responses to light probably do not demand any topological organization in the reconstituted retinocollicular pathway. The present experiments suggest that some cues for appropriate topological organization of regenerated retinocollicular projections are present in the denervated colliculus. However, the possibility of formation of recognizable retinotopic maps may be starkly limited by the small number of regenerated RGC axons that reinnervate the SC and by restrictions on regrowth of axons within the SC. With few innervating axons, the opportunity for either competition or cooperativity among axons in establishing and stabilizing synaptic connections would be minimal. Although the present experiments suggest that the denervated SC exercises some modest influence on the topology of reinnervation by regenerated RGC axons, they do not demonstrate a precisely ordered reinnervation comparable with that seen in anamniotes. Development of strategies to enhance survival of axotomized RGCs (Bonfanti et al., 1996; PeinadoRamon et al., 1996; Di Polo et al., 1998) and regrowth of their 
axons in the peripheral nerve graft (Thanos et al., 1993; $\mathrm{Ng}$ et al., 1995) and CNS targets (Tatagiba et al., 1997; Huang et al., 1999) will clearly be of importance if reconstruction of mammalian visual pathways is to result in more than light perception.

\section{REFERENCES}

Attardi DG, Sperry RW (1963) Preferential selection of central pathways by regenerating optic fibers. Exp Neurol 7:46-64.

Aviles-Trigueros M, Sauve Y, Lund RD, Vidal-Sanz M (2000) Selective innervation of retinorecipient brainstem nuclei by retinal ganglion cell axons regenerating through peripheral nerve grafts in adult rats. J Neurosci 20:361-374.

Bähr M, Wizenmann A (1996) Retinal ganglion cell axons recognize specific guidance cues present in the deafferented adult rat superior colliculus. J Neurosci 16:5106-5116.

Baier H, Bonhoeffer F (1992) Axon guidance by gradients of a target derived component. Science 255:472-475.

Beazley LD, Sheard PW, Tennant M, Starac D, Dunlop SA (1997) Optic nerve regenerates but does not restore topographic projections in the lizard Ctenophorus ornatus. J Comp Neurol 377:105-120.

Bonfanti L, Strettoi E, Chierzi S, Cenni MC, Liu XH, Martinou J-C, Maffei L, Rabacchi SA (1996) Protection of retinal ganglion cells from natural and axotomy-induced cell death in neonatal transgenic mice overexpressing bcl-2. J Neurosci 16:4186-4194.

Boxberg Y, Deiss S, Schwarz U (1993) Guidance and topographic stabilization of nasal chick retinal axons on target-derived components in vitro. Neuron 10:345-357.

Caroni P, Schwab ME (1988) Antibody against myelin-associated inhibitor of neurite growth neutralizes nonpermissive substrate properties of CNS white matter. Neuron 1:85-96.

Carter DA, Bray GM, Aguayo AJ (1989) Regenerated retinal ganglion cell axons can form well-differentiated synapses in the superior colliculus of adult hamsters. J Neurosci 9:4042-4050.

Carter DA, Bray GM, Aguayo AJ (1994) Long-term growth and remodeling of regenerated retinocollicular connections in adult hamsters. J Neurosci 14:590-598.

Carter DA, Bray GM, Aguayo AJ (1998) Regenerated retinal ganglion cell axons form normal numbers of boutons but fail to expand their arbors in the superior colliculus. J Neurocytol 27:187-196.

Chan SO, Guillery RW (1994) Changes in fiber order in the optic nerve and tract of rat embryos. J Comp Neurol 344:20-32.

Cline HT (1991) Activity-dependent plasticity in the visual systems of frogs and fish. Trends Neurosci 14:104-111.

Cohen J, Burne JF, Winter J, Bartlett P (1986) Retinal ganglion cells lose response to laminin with maturation. Nature 322:465-467.

Davenport RW, Thies E, Zhou R, Nelson PG (1998) Cellular localization of ephrin-A2, ephrin-A5, and other functional guidance cues underlies retinotopic development across species. J Neurosci 18:975-986.

de Curtis I, Reichardt LF (1993) Function and spatial distribution in developing chick retina of the laminin receptor alpha 6 beta 1 and its isoforms. Development 118:377-388.

Di Polo A, Aigner LJ, Dunn RJ, Bray GM, Aguayo AJ (1998) Prolonged delivery of brain-derived neurotrophic factor by adenovirusinfected Muller cells temporarily rescues injured retinal ganglion cells. Proc Natl Acad Sci USA 95:3978-3983.

Finlay BL, Schneps SE, Wilson KG, Schneider GE (1978) Topography of visual and somatosensory projections to the superior colliculus of the golden hamster. Brain Res 142:223-235.

Fraser SE, Perkel DH (1990) Competitive and positional cues in the patterning of nerve connections. J Neurobiol 21:51-72.

Galli L, Rao K, Lund RD (1989) Transplanted rat retinae do not project in a topographic fashion on the host tectum. Exp Brain Res 74:427-430.

Gaze RM, Jacobson M (1963) A study of the retinotectal projection during regeneration of the optic nerve in the frog. Proc R Soc Lond [Biol] 157:420-448.

Ghosh A, David S (1997) Neurite growth-inhibitory activity in the adult rat cerebral cortical gray matter. J Neurobiol 32:671-683.

Holt CE, Harris WA (1983) Order in the initial retinotectal map in Xenopus: a new technique for labelling growing nerve fibres. Nature 301:150-152.

Honda H (1998) Topographic mapping in the retinotectal projection by means of complementary ligand and receptor gradients: a computer simulation study. J Theor Biol 192:235-246.

Hua SE, Massone LL, Houk JC (1993) Model of topographic map development guided by a transiently expressed repulsion molecule. Neuro-

Report 4:1319-1322.

Huang DW, McKerracher L, Braun PE, David S (1999) A therapeutic vaccine approach to stimulate axon regeneration in the adult mammalian spinal cord. Neuron 24:639-647.
Ichijo H, Bonhoeffer F (1998) Differential withdrawal of retinal axons induced by a secreted factor. J Neurosci 18:5008-5018.

Keirstead SA, Rasminsky M, Fukuda Y, Carter DA, Aguayo AJ, VidalSanz M (1989) Electrophysiological responses in hamster superior colliculus evoked by regenerating retinal axons. Science 246:255-258.

Liang KY, Zeger SL (1986) Longitudinal data analysis using generalized linear models. Biometrika 73:13-22.

Matsumoto N, Kometami M, Nagano K (1987) Regenerating retinal fibers of the goldfish make temporary and unspecific but functional synapses before forming the final retinotopic projection. Neuroscience 22:1103-1110.

McKerracher L, David S, Jackson DL, Kottis V, Dunn RJ, Braun PE (1994) Identification of myelin-associated glycoprotein as a major myelin-derived inhibitor of neurite growth. Neuron 13:805-811.

McLoon SC, McLoon LK, Palm SL, Furcht LT (1988) Transient expression of laminin in the optic nerve of the developing rat. J Neurosci 8:1981-1990.

Meyer RL, Kageyama GH (1999) Large-scale synaptic errors during map formation by regeneration of optic axons in the goldfish. J Comp Neurol 409:299-312.

Nakamoto M, Cheng HJ, Friedman GC, McLaughlin T, Hansen MJ, Yoon CH, O'Leary DD, Flanagan JG (1996) Topographically specific effects of ELF-1 on retinal axon guidance in vitro and retinal axon mapping in vivo. Cell 86:755-766.

$\mathrm{Ng} \mathrm{TF}$, So KF, Chung SK (1995) Influence of peripheral nerve grafts on the expression of GAP-43 in regenerating retinal ganglion cells in adult hamsters. J Neurocytol 24:487-496.

Peinado-Ramon P, Salvador M, Villegas-Perez MP, Vidal-Sanz M (1996) Effects of axotomy and intraocular administration of NT-4, NT-3, and brain-derived neurotrophic factor on the survival of adult rat retinal ganglion cells. A quantitative in vivo study. Invest Ophthalmol Vis Sci 37:489-500.

Penn AA, Riquelme PA, Feller MB, Shatz CJ (1998) Competition in retinogeniculate patterning driven by spontaneous activity. Science 279:2108-2112

Rager G, Morino P, Schnitzer J, Sonderegger P (1996) Expression of the axonal cell adhesion molecules axonin-1 and Ng-CAM during the development of the chick retinotectal system. J Comp Neurol 365:594-609

Roskies AL, O'Leary DDM (1994) Control of topographic retinal axon branching by inhibitory membrane-bound molecules. Science 265:799-803.

Sasaki H, Inoue T, Iso H, Fukuda Y, Hayashi Y (1993) Light-dark discrimination after sciatic nerve transplantation to the sectioned optic nerve in adult hamsters. Vision Res 33:877-880.

Sasaki H, Coffey P, Villegas-Perez MP, Vidal-Sanz M, Young MJ, Lund RD, Fukuda Y (1996) Light induced EEG desynchronization and behavioral arousal in rats with restored retinocollicular projection by peripheral nerve graft. Neurosci Lett 218:45-48.

Sasaki H, Iso H, Coffey P, Inoue T, Fukuda Y (1998) Prepulse facilitation of auditory startle response in hamsters. Neurosci Lett 248:117-120.

Sauvé Y, Sawai H, Rasminsky M (1995) Functional synaptic connections made by regenerated retinal ganglion cell axons in the superior colliculus of adult hamsters. J Neurosci 15:665-675.

Shatz CJ (1990) Impulse activity and the patterning of connections during CNS development. Neuron 5:745-756.

Siminoff R, Schwassmann O, Kruger L (1966) An electrophysiological study of the visual projection to the superior colliculus of the rat. J Comp Neurol 127:435-444.

Simon DK, O'Leary DDM (1991) Relationship of retinotopic ordering of axons in the optic pathway to the formation of visual maps in central targets. J Comp Neurol 307:393-404.

Simon DK, O'Leary DDM (1992a) Responses of retinal axons in vivo and in vitro to position-encoding molecules in the embryonic superior colliculus. Neuron 9:977-989.

Simon DK, O'Leary DDM (1992b) Development of topographic order in the mammalian retinocollicular projection. J Neurosci 12:1212-1232.

Smith-Thomas LC, Fok-Seang J, Stevens J, Du J-S, Muir E, Faissner F, Geller HM, Rogers JH, Fawcett JW (1994) An inhibitor of neurite outgrowth produced by astrocytes. J Cell Sci 107:1687-1695.

Sperry RW (1963) Chemoaffinity in the orderly growth of nerve fiber patterns and connections. Proc Natl Acad Sci USA 50:703-709.

Stuermer CAO (1988) Retinotopic organization of the developing retinotectal projection in the zebrafish embryo. J Neurosci 8:4513-4530.

Stuermer CAO, Easter Jr SS (1984) A comparison of the normal and regenerated retinotectal pathways of goldfish. J Comp Neurol 223:57-76.

Tatagiba M, Brosamle C, Schwab ME (1997) Regeneration of the adult mammalian central nervous system. Neurosurgery 40:541-546.

Thanos S (1992) Adult retinofugal axons regenerating through peripheral nerve grafts can restore the light-induced pupilloconstriction reflex. Eur J Neurosci 4:691-699.

Thanos S, Mey J, Wild M (1993) Treatment of the adult retina with microglia-suppressing factors retards axotomy-inducted neuronal deg- 
radation and enhances axonal regeneration in vivo and in vitro. $\mathrm{J}$ Neurosci 13:455-466.

Tiao Y-C, Blakemore C (1976a) Regional specialization in the golden hamster's retina. J Comp Neurol 168:439-458.

Tiao Y-C, Blakemore C (1976b) Functional organization in the superior colliculus of the golden hamster. J Comp Neurol 168:483-504.

Udin SB, Fawcett JW (1988) Formation of topographic maps. Annu Rev Neurosci 11:289-327.

Vidal-Sanz M, Bray GM, Villegas-Pérez M-P, Aguayo AJ (1987) Axonal regeneration and synapse formation in the superior colliculus by retinal ganglion cells in the adult rat. J Neurosci 7:2894-2907.

Vidal-Sanz M, Bray GM, Aguayo AJ (1991) Regenerated synapses persist in the superior colliculus after the regrowth of retinal ganglion cell axons. J Neurocytol 20:940-952.

Walter J, Kern-Veitis B, Huf J, Stolze B, Bonhoeffer F (1987a) Recognition of position specific properties of tectal cell membranes by retinal axons in vitro. Development 101:685-696.
Walter J, Henke-Fahle S, Bonhoeffer F (1987b) Avoidance of posterior tectal membrane by temporal retinal axons. Development 101:909-913.

Whiteley SJO, Sauvé Y, Aviles-Trigueros M, Vidal-Sanz M, Lund RD (1998) Extent and duration of recovered pupillary light reflex following retinal ganglion cell axon regeneration through peripheral nerve grafts directed to the pretectum in adult rats. Exp Neurol 154:560-572.

Wizenmann A, Bähr M (1997) Growth characteristics of ganglion cell axons in the developing and regenerating retino-tectal projection of the rat. Cell Tissue Res 290:395-403.

Wizenmann A, Bähr M (1998) Growth preferences of adult rat retinal ganglion cell axons in retinotectal cocultures. J Neurobiol 35:379-387.

Wizenmann A, Thies E, Klostermann S, Bonhoeffer F, Bähr M (1993) Appearance of target-specific guidance information for regenerating axons after CNS lesions. Neuron 11:975-983.

Wong RO, Meister M, Shatz CJ (1993) Transient period of correlated bursting activity during development of the mammalian retina. Neuron 11:923-938. 